\title{
Elite Rugby and COVID-19: Protecting the Wellbeing of Rugby Players and Support Staff from an Occupational Safety and Health Perspective
}

Yanbing Chen ( $\nabla$ yanbing.chen@ucdconnect.ie)

University College Dublin https://orcid.org/0000-0002-3093-2904

\section{Conor Buggy}

Centre for Safety and Health at Work, School of Public Health, Physiotherapy and Sports Science, University College Dublin, Dublin

\section{Seamus Kelly}

Institute of Sport and Health, School of Public Health, Physiotherapy and Sports Science, University College Dublin, Dublin

\section{Original Research Article}

Keywords: Elite Rugby, COVID-19, Occupational Safety, Health Perspective, Support Staff

Posted Date: August 24th, 2020

DOl: https://doi.org/10.21203/rs.3.rs-59442/v1

License: (9) (1) This work is licensed under a Creative Commons Attribution 4.0 International License. Read Full License 


\section{Abstract}

Background: The contact nature of rugby with its' intensive physical interaction often exposes players to a high risk of injury and illness. Compliance with prescribed safety guidelines when returning to play during the COVID-19 pandemic is important for both rugby players and their support staff's health and wellbeing. However, elite rugby has an inherent level of risk acceptance that has been a cultural norm in the game for decades. This paper aims to identify risk factors that influence players' awareness and actions in relation to the highly communicable disease COVID-19, and provide rugby clubs and associations with practical return to play solutions from a health and safety perspective.

Methods: This study thematically analysed interviews with 15 senior rugby support staff employed in elite rugby union that explored key factors impacting health-and-safety in elite rugby. With the emphasis on rugby players' health-and-safety awareness (e.g. illness/injury reporting awareness) and rugby environment micromanagement (e.g. player hygiene) and rugby physical contact nature, analysing the factors that may be normalised in elite sporting settings in the context of managing return to play during the COVID-19 pandemic.

Results: Due to physical contact nature of rugby, players are exposed to the risk of trauma resulting in skin abrasions and lacerations etc. which may aggregate the risk of infectious diseases. A level of micromanagement practices such as player hygiene management and health condition surveillance that builds on the current situation are effective and essential, considering rugby players in a high level of fitness condition and at a relatively young age can be overly confident with their ability to deal with the risk of illness. Furthermore, player awareness such as symptom reporting and return-to-play (RTP) after unwellness is due to improve for ensuring their health and wellbeing and of their fellow players as well as support staff during the back to field process in the context of COVID-19.

Conclusions: Returning to rugby practice and competition will require a level of micromanagement and player safety awareness education in order to achieve the goal of optimally protecting the players from potential illness and / or spreading it to fellow players and support staff. Rugby rituals such as the New Zealand haka could be considered for keeping social distance between players while affirming the rugby nature of aggression exhibition.

\section{Key Points}

- A micromanagement approach in rugby organisation may achieve the goal of optimally protecting the players from potential injury and illness while returning to the field during the pandemic.

- Elite rugby players are generally in a high level of fitness condition at a relatively young age which may mislead the players to be overly confident with their ability to deal with injury and illness risk.

- Rugby rituals such as the New Zealand haka could be considered for keeping social distance between players while affirming the rugby nature of aggression exhibition. 


\section{Introduction}

The COVID-19 pandemic has impacted all elite sport events through severe restrictions to reduce the likelihood of disease transmission to athletes, support staff, ancillary event staff and audiences. In particular, team sports have been significantly impacted with some still not returned to a practice and / or competitive environment. Given the amount of physical contact involved in team sports and elite rugby union in particular, the process of returning to the field for practice and competition will be challenging for both players and their supporting staff. Recently, World Rugby has developed a set of guidelines for a safe return (Return to Play-RTP) to rugby union activities during the pandemic [1] and many of its affiliated member unions are in the preparation phase of returning to training and competition $[2,3]$.

In 2006, a literature review of medical publications that reported on infectious disease outbreaks in competitive athletes from 1966 to 2005 identified the most common transmission mode in outbreaks was mainly skin-to-skin contact [4]. For example, herpes simplex virus infections were common among wrestlers and rugby players and Methicillin-resistant Staphylococcus aureus can cause outbreaks of soft tissue and skin infections among collegiate and professional athletes [5, 6]. More recently, a similar review in 2012 indicated that most infectious disease outbreaks in competitive sports recorded from 2005 to 2010 occurred in close-contact sports especially combat sports involving collegiate competitors [7]. For team sports in particular the environments where athletes compete, practice, receive therapy for injuries, and travel both domestically and internationally, provide varied opportunities for the transmission of infectious organisms [4].

Substantial RTP guidelines have been published recently [1], however, to ensure those guidelines are strictly followed, players and their support staff and families must have a strong awareness level of occupational safety and health (OSH). The prevailing culture of risk tolerance in elite sports [8] and for winning at all costs [9] raises significant concerns in relation to how team sports can adapt to the conditions imposed by the COVID-19 pandemic. In particular, team sports are an optimal environment for the rapid spread of the virus which can have a significant impact on players and support staff [10]. When considering that high intensity exercise may dampen the immune system of even the healthiest athlete, the potential for increased susceptibility to COVID-19 infection in athletes needs to be at the forefront of the minds of all athletes and support staff [1]. The implication of this is that the individual athlete will need to be even more aware of their own health condition as well as their teammates and supporting staff and should be prepared to accept increased monitoring and reporting.

There have been a number of reported outbreaks of infectious diseases amongst rugby players since the close physical contact and trauma inherent in playing rugby facilitates transmission of viral, bacterial and fungal pathogens between players [11]. While infection control can be included within effective health and safety management practices, competitive sporting culture by its very nature can conflict with the promotion of a positive safe working environment for elite athletes. For example, in elite rugby union, as players tend to have a high-risk acceptance influenced by traditional rugby culture associated with performance of masculinity, fearlessness, pain tolerance, etc [12-14], returning to play when the sport 
culture is permissive of risk tolerance should be a cause of apprehension. Safety culture consists of shared values, attitudes, perceptions, and beliefs that drive decisions and behaviours regarding safety [15], and can be manifested by human workplace behaviours as a part of organisational culture [16, 17]. In a sport team, players' perception of risk can be largely influenced by surrounding social referents (e.g. teammates, coaches, physiotherapists) with most elite players that are still at a younger age are more receptive to such positive influential behaviour $[18,19]$. When a positive safety management culture is fostered by all individuals in an organisation, positive behavioural change that is measurable ensues, a situation that can be equally true in any sporting organisation that places an emphasis on safety.

In order to improve rugby players' and support staff compliance with health and safety guidelines for RTP during the COVID-19 pandemic, this study emphasises two aspects: rugby players' health-and-safety awareness (i.e. awareness education, reporting awareness and RTP after illness/injury) and micromanagement by support staff (i.e. hygiene, staff support and physical interactions). The findings can facilitate rugby organisations in optimally ensuring the health and wellbeing of their players and staff by reinforcing their management strategy with a pertinent research evidence basis.

\section{Methodology}

This paper is located within and arises from a larger study that explored aspects of OSH management within elite rugby union in Ireland. In response to the demand of a safe return to elite rugby in the context of the current pandemic, this paper explores key health and safety factors that may improve rugby players' compliance with new guidance that has arisen as a necessity to RTP during the COVID-19 pandemic. The data presented in this paper are drawn from a dataset comprising health and safety related information that was collected prior to the emergence of the COVID-19 pandemic (2019) using semi-structured interviews with 15 elite rugby supporting staff (Table 1) in Ireland. As Ireland has a wellestablished rugby culture with supporting organisations at international, national, regional and local level, the data from this study can be considered representative for all rugby organisations considering RTP during the current pandemic.

\subsection{Data Collection}

The first author conducted all the interviews by using the interview protocol developed around health and safety issues in sports (Fig. 1) identified from key factors that were highlighted in a prior literature review and research conceptual framework development [9]. All the interviews were recorded with participants' consent and transcribed by the first author. Research ethical approval was granted by the university Human Research Ethics Committee. The document "Safe Return to Rugby - in the Context of the COVID19 Pandemic" developed by World Rugby [1] aligned to World Health Organisation (WHO) provides guidelines and recommendations for national and local rugby associations and unions which provided a basis to evaluate the data from the perspective of health and safety management during the pandemic.

\subsection{Data Analysis}


The first step in our analysis involved identifying and analytically coding data in the interview transcripts. Specifically, the first author coded data that was relevant to rugby safety return based upon the premises put forward by the World Rugby document [1]. A codebook was subsequently developed by the first author. In terms of rigour, the data and the primary coding result were sent to the second author. The second author refined the coding and sent the revised version of codebook back to the first author. In accordance with the feedback, the first author attuned the codebook and sent it to the second author for a follow-up feedback refinement. This coding process between the two authors was repeated several times with the third author acted as a "critical friend" by challenging the codes and providing detailed reflections during the process $[20,21]$. The codes and themes were constantly updated and refined until all authors were satisfied with the codebook. Table 2 provides an extract of the codebook. Following consensus, the first author re-coded the interview transcripts using the updated codebook. During this stage, similar type of codes were grouped into key themes. The next stage involved a thorough reevaluation of those themes to develop categories from the perspective of $\mathrm{OSH}$. This stage involved a critical discussion amongst the authors on what aspects of pertinent OSH management processes in the data was considered most relevant to the current pandemic context referring to the "Safe Return to Rugby" document developed by World Rugby [1] and "Return to Work Safely Protocol" published by Irish Government [22]. The authors have specialisation in sport management, occupational safety and health and adult education / universal design disciplines. Finally, three key categories were identified (micromanagement on health-and-safety, player health-and-safety awareness improvement and rugby physical contact nature) after this non-linear, iterative coding process between the co-authors. The framework including a hierarchy of categories, themes and codes pertinent to the COVID-19 pandemic identified is presented as Table 3. Furthermore, the appropriate narratives were used to reflect the key themes in the Findings section.

\section{Results}

The findings are presented from the three categories highlighted in Table 3: micromanagement on healthand-safety; player health-and-safety awareness improvement; and rugby physical contact nature. The first category focuses on players health-and-safety related visible actions which are monitorable and instructional by rugby management staff. The themes included are player hygiene and player health condition surveillance. The second category is directed at the importance of improving players healthand-safety awareness, which is critical for ensuring players fully understand and follow safety return guidelines. The themes included are player awareness education, player reporting awareness and RTP after unwellness. The third category focuses on the physical contact nature of rugby that may be of concern as a particular risk during COVID-19 pandemic, such as collisions and tackle on the pitch. All categories and subsequent themes were illustrated with interviewees' quotes for readers' understanding and consideration. Interviewees are designated as P1 to P15 to maintain anonymity and confidentiality.

\subsection{Micromanagement on Health-and-Safety}

\subsubsection{Player Hygiene}


While highly susceptible to infectious diseases due to close physical contact and potential bodily fluid interaction (sweat and saliva), most infectious diseases are preventable among rugby players by promoting good hygiene practices in the changing rooms and on the field of play [4]. Rugby organisations usually pay more attention to player hygiene when preparing for an upcoming competition, as $\mathrm{P} 12$ suggested, the precious opportunity to attend an international sports game may be ruined because of a player's bad hygiene habits.

We educate players on hand washing and provide alcohol gel in camps and things like that. Because if somebody gets a trouble, or gets the flu or chest infection, they can't perform. It doesn't matter what they've done. And with training. And it's the same when you see like things like the Olympics. And you know, people trained for four years and they eat something dodgy and get a bug and it's all gone. And so we will be trying to promote that from very, you know, from the young players come in to representative sides like just hand washing, and not sharing water bottles. (P12)

Since infections can spread from one player to another by direct contact between broken skin, mucous membranes, infectious lesions and secretions, the worst consequence in the current pandemic context could be an outbreak of COVID-19 if one player becomes infected and contaminates other players and staff without exhibiting any symptoms. It is common for rugby players to share the use of communal items such as water bottles, rugby kit, towels and other equipment during daily routines. Because the lifespan of COVID-19 on various surfaces ranges from hours to days [23], this will be a significant issue for RTP. Therefore, specific hygienic habits such as frequent hand-washing, frequent cleaning of personal equipment and kit and the priority use of individual equipment should be developed among the players as part of their daily routine for illness prevention rather than a preparation just for competition, as P13 suggested:

Well, you know, what do they do in terms of um, preventing getting ill? So do they wash their hands? You know, you know whatever behaviours so do you wash your hands? Do you use it? You know you come into a cafe and then and wash your hands. Uh, do you get vaccinations and what do you do around your eating? You know. Um, so what are the behaviours that they are showing? So how do they act around other people who are sick and not well, and where you know so if somebody was sick ... you are you know this way. So, so looking at what they do at a behaviour level that might show that they have an awareness of their own health. (P13)

The micromanagement of specific health and safety control measures relating to hygiene involves physical distancing, hand hygiene, mask-wearing, the prohibiting of team handshakes, on field spitting, and sharing of drink bottles and towels. These restrictions can be challenging, so appointing a field health and safety officer to ensure players follow the prescribed hygiene guidelines can be considered a necessity for RTP [24].

\subsubsection{Player Health Condition Surveillance}


In rugby, medical staff play an important role to keep players' healthy and safe, but the interaction between players and medical team may also cause the concern during COVID-19 pandemic. In an elite rugby team, players with unwell symptoms can immediately be assessed, diagnosed and treated by the medical team in the rugby club, as P12 described:

Yeah, if anything goes in and goes, oh, I have a bit of a sniff, a little bit of a cold. They'll be given like a nutritionist downstairs. She gives off and gives them a little pack. And it has like vitamin $C$, zinc and hydration like you know, uh, maybe get more sleep or you know, what, what they're changing might be adopted... (P12)

However, in this instance, medical support is primarily aiming to maximise players' fitness and readiness to perform rather than ensuring their general health and wellbeing or indeed that of other players and support staff. The focus is on the individual rather than the potential impact on collective health and wellbeing.

We would have protocols then around the player in terms of entry medicals. So we do entry medicals on them. We do exit medicals. It's the whole load of process and procedures to ensure that health and safety be that from their wearing, be that from how we manage certain injuries analysis to how we screen them, whatever. And then there is the whole system of support we put around them, medical to ensure that they stay healthy and perform to the best. Because in the elite environment, it's not just that you want them healthy, we want them healthy and performing to their best. (P13)

In relation to an individual infection this level of medical consideration is appropriate. However, given the nature of COVID-19 and its capacity to infect people in contact, collective health and wellbeing needs to be considered. As an individual's health condition is significantly related to their ability to resist infection, the professional treatment and advice from medical team is essential to support individual players health and the capacity for their safe return to play. But now that medical treatment must be cognisant of the potential impact to other people surrounding the individual during illness and when they return to play. In particular, medical staff need to pay special attention to blood injuries which could occur which may expose players to a greater risk of infection than previously considered for biological infections such as herpes simplex virus and Staphylococcus aureus [4]. As aforementioned, medical support staff are usually accessible at pitch-side during the match day to provide the players within match time treatment once accidents / incidents happen.

We had the physio on site and from an injury point of view, you know, you're looked after on pitch, they were, they were there all the time. You would see the physio and be treated (P6)

Nevertheless, this type of spontaneous contact between medic staff and player implies that it cannot be adjusted to consider the requirement of social distancing as the very nature of such treatment is to ensure the evaluation of health and prevention of further ill-health. By necessity the medical staff must physically interact with the players, just as primary healthcare workers are inevitably exposed to confirmed Covid-19 patients [25]. Consequently, precautionary measures will need to be taken for close 
contacts that are often spontaneous. In addition, specific controls will need to be adopted to reduce the potential for infection such as specific personal protective equipment for medical support staff (e.g. face shields with an underlying face mask, disposable smocks and gloves). All such physical interactions will need to be logged during a match and if any subsequent infectious disease symptom occurs decisions will need to made in relation to suspension of activities and contact tracing in line with specific guidance [1]. To minimise the risk, non-essential personnel should avoid treatment areas in accordance with the social distance guidelines [26]. Additionally, physiotherapists must ensure hand hygiene before and after treatment and encourage athletes to shower before and after treatment. If unwell, team medical staff must not provide treatment to an athlete in an effort to prevent cross contamination to another athlete or staff member. Unwell athletes should be instructed to see their own general practitioner and must not receive any other type of medical servicing such as injury assessment from the team medical staff until they have been cleared as COVID-19 free [26].

Normally, a principal aspect of the function of a referee is to make on-the-fly decisions from a neutral perspective to ensure the game is carried out following established rules and norms of play. As interviewees explained, the role of the referee is crucial to players' safety during competition:

First, my first issue is the safety that player, when that secured, then I'll decide as a referee whether it's foul play or not. So my number one issue is not, oh, oh my goodness, that's foul play. I worry about that player in a minute. I, my number one concern is what, so what happened? And do I need to stop the game for this player. Once that happen, if the answer to that is yes, that's the first primary focus. And then when that, when people have arrived on the scene to treat that player, the referee is no longer needed at that stage, then they can move to stage two, which is, right, what caused this? Do I need to do anything but to address it? (P10)

Referees are critical to health and safety. In fact, they're probably the most important. Referees' first job is to make sure that the game's run in a safe manner... If the referees control of the match, that's the point where the health and safety of the players can come into question. (P11)

So the role of the referee yes, is very important. And he is the first point of contact and he will call on the medical staff or the physio or anybody else that he thinks is needed. He will stop the match. So yes, his role is important. (P7)

The referee as an authorised party with commanding power on pitch is vital for ensuring players' healthand-safety on the pitch, they therefore need to be cognisant of the transmissibility processes of COVID-19 especially when there is a minimum number of stakeholders that are required to deliver a rugby match safely to avoid the possibility of virus transmission [1]. If a limited-contact version of rugby game was developed in the pandemic context [27], the referees will need to be trained with the updated rules to be capable of immediately distinguishing a foul play that could have ramifications for COVID-19 infection.

Health surveillance systems have been prevalent in professional level rugby to maximise team performance by timely evaluating individual player's health-related condition [28]. Consequently, most 
players have already adapted to this level of micromanagement as a form of health and wellbeing monitoring.

Kidman is an online software, we spend a lot of money on having every player is on there, every player has a profile. And on it or their, in the illnesses and everything is managed the training that they do. And that all of our doctors and physios if they see a player, they're putting all the information on there about what they've done, what they've seen and what. And so then, we know exactly what players are sick or injured...if somebody's appetite is always like ten of ten, they love their foods, they're always on ... and suddenly drops to six, and the alert will pop up on Kidman. So there're the team like the physio where the doctor, coach will see it and they know to go checking with the players and say, you know, you ok? (P12)

So once again using technology like gps trackers, heart rate monitors, those sorts of things to be able to be individually looking at players in a training environment and, and remove them from training if they're starting to hit, um areas where injuries might be a high risk than usual. (P14)

In addition to the management of player performance, the application of a software, as P12 mentioned, could be highly significant for COVID-19 risk management. Such software could be utilised as a mechanism to assist in contact tracing processes within teams which can then aid decision making on return to play. The ability for support staff with responsibility for health and wellbeing to access continuous health monitoring and potentially an expanded version including COVID-19 symptom monitoring would be invaluable for protecting the whole team and support staff unit. Health monitoring where players can daily report their temperature and potentially other COVID-19 symptoms could trigger the order by medical support staff for a COVID-19 test and a temporary precautionary suspension of play until a negative result was returned. This would require players to be honest and transparent in their selfreporting for the benefit of the team and their support staff. Medical support staff with access to such ongoing health monitoring can thus assist in contributing to more informed decision making with management on RTP, participation in practice and competition. Medical support staff could also liaise between teams during competition to share such health data to ensure protection across a league though other playing levels of rugby may not be able to afford such as an advanced application, as P2 suggested, the frequent check points are also applied to make sure the ongoing monitoring:

So, there's check points in the air of starting the season, mid-season, and season off season. And that's checking in physically, mentally, socially results of contract decisions, those some points during the year. And then it's the ongoing monitoring. So, it's making sure day to day, week to week, that they're physically, mentally, socially coping with being a professional rugby player. (P2)

While COVID-19 contact tracing processes [29] in a rugby setting may be considered extremely onerous by players it is essential that players buy into the process for the protection and care of the team as well as their own families and personal social networks outside of the rugby setting. It is of paramount importance that rugby players and all support staff keep track of all contacts that they are having on a continuous basis until the global pandemic is over and vaccines and treatments have been introduced to wider society. If a player or support staff comes in contact with a positive or presumptive positive case of 
COVID-19, that individual should immediately self-isolate from their team and undergo a test. Only when their test is returned as negative can they return to play or to actively support the team.

\subsection{Players Health-and-Safety Awareness Improvement}

Currently, there are various RTP guidelines published in sports research literature this year [2, 3]. that indicate a high level of health and safety awareness is the premise to ensure that players strictly follow those guidelines so that both players and staff can be protected from the risk of COVID-19.

\subsubsection{Player Awareness Education}

Awareness of the potential for COVID-19 to infect and impact all age groups is crucial to having the populace understand the disease. Many young people are under the impression that they cannot be infected or that if they are infected the symptoms will be mild and while $80 \%$ of global cases are asymptomatic or mild [30]. The disease has an impact on all age groups regardless of how healthy individuals are at the time of infection. In Ireland, up to midnight on 24 June, 2020, the incidence of COVID-19 between 15 to 24 year olds was 1885 (7.42\%), between 25 to 34 year olds is 4257 (16.76\%) [31]. Elite rugby players generally perform with a high level of fitness from a relatively young age which may mislead some players to be overly confident with their capability to withstand illness. The lack of health and wellbeing awareness amongst young players has been noticed by our interviewees:

Well, lots of players say it would be very common in an elite sports. The players take a lot of uh, sleeping tablets. So they play in high pressure games, often at night and they can't sleep. And but the, the culture in amongst our medical staff will be very against, that actually don't work and pay players get the addiction and they're not very good for your health. (P12)

Some, some players would be very, very committed to their own, uh individual and team welfare. And others, I would suspect probably put the result in the performance maybe about their own health and wellbeing on occasions. (P14)

The relevance of appropriate health focused education for players in order for them to recognise their own health and wellbeing is thus now of even greater importance due to COVID-19. Players and staff will need to be aware that their own health can impact others on their team, linked with the importance of open and honest reporting of their health / potential COVID-19 symptoms. Individual and collective health and wellbeing awareness level elevation as a result of COVID-19 has the potential to override the performance driven impetus that is embedded within rugby culture. Considering the pressures from peers and career as P7 and P2 described, it is challenging for young rugby players to have a sufficient awareness of their own welfare and how their own individual health status can impact their fellow teammates and support staff.

You know, um, they don't want to be seen to be the weak in... among their peers. They want to be seen to be as good or as healthy as the next guy. So from the point of view, how do they deal with it purely on peer pressure. (P7) 
So how do you build in health and safety where you can actually you've got a one-year contract, you need to prove yourself on your injured for half of it and or the bulk of it and your that's ok. But yes, from an economic, from a sports perspective, they know if they do that come the end of the year, there won't be another contract. So, there's a big conflict there between what's actually going from a health and safety perspective. But what's goanna happen practically from the professional sports environment? They're really at odds. ( $P 2)$

Thus, player COVID-19 specific awareness education can reinforce the promotion of existing best practices. For instance, if players have ancillary concerns such as pressure from peers and contractual implications, they might not want to prioritise safety compliance behaviours which emphasises the importance of micromanagement to alleviate those concerns. The required behaviours (e.g. regular handwashing, covering mouth and nose with a tissue or sleeve during coughing/sneezing) need to be monitored intensively, assisted by a fair safety compliance incentive mechanism [32].

\subsubsection{Player Reporting Awareness}

Elite rugby players usually report unwell symptoms to their medical support staff for appropriate treatment motivated by curing the illness and injury in order to return to play as soon as possible.

the player has to be honest and open and frank with his superiors be they are the coach, are the doctor, or the physio that if he has an injury or if he has a difficulty with his site, or any other aspect of this physical wellbeing that he admits this and he explains to the professionals what the problem is to allow them to treat it...And a lot, and a lot of players are slow sometimes to admit that they have an injury in the hope that it might go away.... Well, their motivation for recovering from illness or injury is to play on the team. So therefore, they will immediately ensure that whatever treatment is required, whatever professional they have to see they will do that. Because they want to get back playing as quickly as possible. So it's fairly simple motivation. They just want to get back and be fit and be ready for selection for a team. But you know, it's slightly different to somebody that's out of work and maybe doesn't like their job. (P7)

Thus, if the symptom of an injury or illness does not limit the player's performance, the reporting awareness will be influenced by their understanding of the severity of the health consequence, as P12 mentioned:

And sometimes it's, I think under, getting their understanding of, do they understand how important it is that they're honest with medical staff about different injuries, their illnesses and their understanding of long term effects of doing certain things, like if they're taking sleeping medications, if they are taking antiinflammatory because they can go to the pharmacy as same as you. (P12)

In the new norm of COVID-19 players could underestimate one of the many symptoms of the disease and either not disclose it to support staff for fear of being suspended from play or play on through ignorance of the disease without realising the impact it could have on their team and potentially an opposing team through infection. Education on COVID-19 should therefore focus not only on a thorough explanation of 
all potential symptoms of the disease but also on players' understanding of the risks to themselves as well as teammates, support staff and opposition players and staff. Players should be educated that erring on the side of caution with potential symptoms could prevent a worst-case scenario of COVID-19 transmission throughout a team and their support staff, and in an extreme incidence cross infection to an opposing team following a competitive match.

As previously mentioned, open and honest health reporting will be necessary moving forward with COVID19 , however a players' reporting behaviour may also be heavily influenced by the culture within their rugby team, as P8 denoted:

I think it's a culture thing. But I don't think anyone is ever going to say oh, we're not gonna talk if we get injured. We're not going to say if we don't feel ready to train or feel unwell. So I think just, their mutual respect for each other, and just building a culture and a team is the biggest factor. I don't think there's any, I don't think it's a matter that would be in certain teams or squads. I get this. I get that. I think it's just an understanding that you can talk. It's okay to talk and that's changing massively. (P8)

According to the legislation in most developed countries, employees are responsible for their co-workers' health-and-safety in their workplace. As players in parallel, reporting the unwellness is not only for their own individual sake, but also for protecting other players and staff from the potential risk during pandemic. Therefore, players will need become individual leaders and encourage each other to report all potential symptoms and their contact histories with confirmed or suspected COVID-19 cases, and if necessary may be required to undergo testing, self-isolation and suspension from play as an exercise in individual perseverance to benefit team integrity [33]. A culture of transparency and honesty accompanied by an elevation of team unity in the face of COVID-19 (i.e. one for all and all for one) has the potential to ensure rugby teams get through the pandemic relatively unscathed.

\subsubsection{RTP after Unwellness}

RTP decisions are complex depending on type of sport, and often influenced by various factors as existing models suggest [34]. A further consideration is that players' anxiety may be elevated by a number of unanticipated facets of an extended period of modified training due to COVID-19 [35, 36], which might impact on injury risk when returning to play [37]. In rugby, it is difficult to have a clear-cut procedure for players' RTP decision-making, be it an injury, illness or other symptoms. This is problematic because some participants thought it should be the responsibility of medical staff, some indicated that it was the player who actually made the decision, and some participants denoted it was a collaborative decision as clinical practitioners suggested [38].

The medic, the trained medical staff will make a decision that they are not allowed to participate... I think they're probably is a window where it's a collaboration with the, the player has some ownership to make a decision as long as I fully understand, yeah, and the risks associated with that and those risks are not really that severe. (P14) 
Though medical decisions can largely ensure a player's wellbeing, in the environment of a rugby organisation, the medical staff are usually the most conservative party among the stakeholders, as P3 said:

It's like actually where's the responsibility layer who has the ultimate saying what these players do and, you know, that's that's, that's kind of... grey area like might be too idealistic to say that it always rests with the medical team because the medical team activity going to be pretty conservative and even if you look at, you know, some outcomes in certain areas where medical team are given full control of the topic and the outcome then, always, they don't always do actually what the evidence says themselves. (P3)

After all, medical staff have the direct responsibility if a player's health condition is getting worse because of RTP. For medical team's view, ill or injured players had better not play until there is no risk of RTP for players health sake and medical team duty's sake.

I'm fine to go, I wanna go back on blah blah..." Our medical staff would have seen something they know "No, you're not." And they just don't like them, our medical staff. There's no question that if they think somebody's off, nobody questions, not. And it's, you know it's I think our medical staff are very well respected here in Ireland (P12)

So if there's any questions whatsoever, it's referring to the medical team and it's their responsibility. It's not in the player's hands to decide whether they play or not. It's always taken out of their hands where are possible. (P8)

Coaching staff usually respected medical decisions despite the nature of some RTP decisions being disappointing for team morale or team effectiveness in competition, but the decisions are understood that fully recovery is the premise for players to participate in more competitions. As P5 explained:

I suppose when I look at health and safety in general, you know, that's where coming... and I suppose I would have protocols, how we look at different injuries and plans to what happens, so that's why we have traumatology training, in terms of dealing with them at pitch side situation.... Sometimes the players I had a game, earlier this season, where a player came to me and said 'I don't feel good, I need to come off'. So that's generally the exception rather than the rule. That's not the most common thing would happen. But in terms of the coaching staff, they're happy for me to make the decision whether the player can continue or not. And I would generally tell them so like I said have a relationship with the player. You're able to say, look, you know you're not right, I know you're not right. We know you're for the team on the field, but you don't have to be on the field, we can bring the player from the side-line who is fit. (P5)

The opinion of medical staff is undoubtedly important as they are the healthcare professional with the expertise including the short-term risk of performance detriment or re-injury, the consequences of infection, re-injury and other long-term health (and performance) risk for all players in the club. In light of COVID-19 the opinions of an informed and observant medical support staff are of even greater importance. The above quotes reinforce previous assertions regarding open and honest health reporting 
and an acceptance that micromanagement of their health will be a necessity moving forward. If a player does not to report an unwellness suffered and continue playing, medical staff would have no chance to provide in-time treatment, request appropriate testing, make recommendation on suspension from play or any other professional healthcare opinion on RTP which could have very serious consequences to the team as a whole unit in light of COVID-19. Players' reporting awareness need to be evaluated and educated especially for infectious diseases such as COVID-19 and any injuries or illnesses that could have long-term health and wellbeing consequences to a player long after they have retired from the sport competitively.

\subsection{Rugby's Physical Contact Nature}

Since professionalism, rugby has increasingly become more competitive with greater manifestation of aggressive physical interactions between the players [39]. As the examples given by the interviewees:

I think in rugby we're looking at lowing the level of the maximum tackle to nipple line. So again, that means that you know, people are tackling above it is too high. That's a risk factor. (P5)

I think something like tackling technique can be worked on... Some people just don't have good tackling technique and maybe they do get hurt because of it. (P6)

The biggest challenge I suppose in the professional era is because the collisions and because the contact between players is now quite aggressive is and it's very strong and they collide and crash into each other so much, that is very important that the level of fitness and their mental approach. I mean a simple thing like to avoidance of a big dangerous tackles to move out of the way perhaps that, all of that is still in their brain, all impact on their personal safety. (P7)

Due to physical contact nature of rugby, players are exposed to a high risk of trauma resulting in abrasions and lacerations of skin. Infections can thus be spread from one player to another by direct contact via broken skin [4]. Similarly, the nature of intense cardiovascular exercise induces greater production of sweat, greater exhalation and greater saliva production. Consequently, COVID-19 can have greater potential during training and competition to be transmitted by increased exposure to bodily fluids, particularly from water droplets as exhalent from the lungs. Given the level of intentional and incidental body contact and close quarters involved in rugby, there is an acceptance that these will be the last aspects of the sport to return to the field.

\section{Discussion}

The findings presented have practical implications for RTP as well as the future of rugby culture. Rugby organisations need to extend their capacity to strengthen the micromanagement of player health and wellbeing as this is already an established approach for maximising performance [40]. Professional / elite players are generally well used to following instructions which aligns to their purpose of achieving an aimed for performance. For other playing levels, rugby clubs may not have the required resources to 
adequately fulfil the level of micromanagement required by COVID-19 such as the technological support and health knowledge for contact tracing and real-time health data detection. Furthermore, semiprofessional players and high-performance amateurs may potentially have more social activities with people outside the rugby community since rugby may not be their future career. To reduce the risk of COVID-19 resulting from players' broader social and familial contacts, it is crucial to improve the players' health and wellbeing awareness including ongoing health monitoring and being receptive to honest reporting of COVID-19 symptoms while also embedding the concept that all in the team are working together collectively to protect the whole teams health and wellbeing. Take player hand hygiene as an example, existing handwashing guidelines can already be very detailed, but now the focus should be the development of specific hygiene habits by embedding those guidelines into the day-to-day mindset and culture of a team as a way to protect and support the whole team instead of purely forcing mechanical handwashing behaviours.

Even though epidemiological data indicates that older people with underlying comorbid diseases, including obesity, are at greater risk of developing adverse clinical outcomes that does not mean that healthy young athletes cannot develop severe respiratory complications [41]. Recent studies indicate that aside from respiratory complications, COVID-19 might generate serious complications related to cardiovascular [42] and nervous systems [43] that might lead to hospitalisation and even death. Physical activity during the asymptomatic phase of the COVID-19 illness or premature return to sporting activities, especially intensive physical practices after the infection, could have serious health implications. Given the absence of standardised guidelines for RTP after infection, a conservative approach has been justifiably advised [41]. Educating players and all support staff on the implications of contracting COVID19 is thus essential in order to elevate the knowledge within teams but also as a means to justify such a conservative approach to the control measures and behaviours needed for RTP.

Based on the physical contact nature of rugby, the possibility of a non-contact (or limited contact) variant of the game in the context of social distancing should be discussed. If the levels of contact in rugby can be downgraded, both injury and illness risk will correspondingly be reduced, however many would argue that rugby without the physical contact is nothing more than tag rugby. Since sport is always a controlled battle in an imaginary setting, it is in some sense 'unreal' or 'hallucinatory' [44] and that would potentially be lost in a non-contact or limited-contact version of rugby. Keeping the risk low while keeping the enjoyable battle-excitement high through the civilised sport rules will thus need to be considered. To reduce physical contacts in rugby, rugby rituals practiced in individual countries such as the New Zealand haka could be considered as a way to affirm the competitive nature and adrenalin rush but do so in a controlled way that is respectful of opposing teams health and wellbeing while also meeting the need for the sense of belongingness within a team. For spectators, the aggression manifested by such rituals can go towards replacing that derived from physical contacts as well, considering that the haka has been always popular and attractive as a pre-match ritual. For rugby organisations, the management can build their brand by rituals such as an impressive haka as a manifestation of a strong sense of responsibility for their players health and wellbeing in the context of pandemic. 


\section{Conclusion}

Considering the nature of rugby as a collective sport with intensive physical interaction between players including both collaboration and opposition, the contact nature of the game may expose its participants to a high risk of injury and illness. From an OSH perspective, a micromanagement approach in the organisation may achieve the goal of optimally protecting the players from potential injury and illness while returning to the rugby field. In addition to the fact that elite rugby players are generally in a high level of fitness condition at a relatively young age which may mislead the players to be overly confident with their ability to deal with injury and illness risk during training and competition, the education on players awareness towards health and wellbeing is essential during the back to field process, importantly including the awareness of COVID-19 symptoms and their honest reporting.

\section{Abbreviations}

RTP: return-to-play

OSH: occupational safety and health

WHO: World Health Organisation

PPE: personal protective equipment

\section{Declarations}

\section{Ethics approval and consent to participate:}

Research ethical approval was granted by the university Human Research Ethics Committee and all participants consented to participate.

\section{Consent for publication:}

Following the research ethical approval, this paper is consented to be published as all participants have been de-identified.

\section{Funding:}

This study was supported by a grant from Chinese Scholarship Council.

\section{Availability of data and material:}

The datasets generated during and/or analysed during the current study are not publicly available due to GDPR compliance.

Competing interests: 
Not applicable

\section{Authors' contributions:}

All authors were involved in the design and concept of the study. YC conducted the interviews, analysed the data and drafted the manuscript. CB examined the coding process, updated the codebook and provided critical OSH insights to the theoretical framework. SK acted as a critical friend challenging the study process to ensure the rigour. All authors provided critical input and final approval.

\section{Acknowledgments:}

The authors express gratitude to the UCD-CSC scholarship scheme supported by University College Dublin and the China Scholarship Council.

\section{References}

1. Falvey É, Mathema P, Horgan M, Raftery M. Safe Return to Rugby-in the Context of the COVID-19 Pandemic. 2020.

2. IRFU. Irish Rugby I The Behind-The-Scenes Operations Of Irish Rugby's Return To Training [Internet]. 2020 [cited 2020 Jun 19]. Available from: https://www.irishrugby.ie/2020/06/19/the-behind-thescenes-operations-of-irish-rugbys-return-to-training/

3. New Zealand Rugby. New Zealand Rugby COVID-19 Level 2 Return to Training Guide [Internet]. 2020. Available from: www.newzealand.rugby/covid-19

4. Turbeville SD, Cowan LD, Greenfield RA. Infectious disease outbreaks in competitive sports: A review of the literature. Am J Sports Med. 2006;

5. Benjamin HJ, Nikore V, Takagishi J. Practical management: Community-associated methicillinresistant Staphylococcus aureus (CA-MRSA): The latest sports epidemic. Clin J Sport Med [Internet]. Clin J Sport Med; 2007 [cited 2020 Jul 1];17:393-7. Available from: https://pubmed.ncbi.nlm.nih.gov/17873553/

6. White WB, Grant Kels JM. Transmission of Herpes Simplex Virus Type 1 Infection in Rugby Players. JAMA J Am Med Assoc. 1984;

7. Collins CJ, O'Connell B. Infectious disease outbreaks in competitive sports, 2005-2010. J Athl Train. 2012;

8. Schnell A, Mayer J, Diehl K, Zipfel S, Thiel A. Giving everything for athletic success! - Sports-specific risk acceptance of elite adolescent athletes. Psychol Sport Exerc. 2014;

9. Chen Y, Buggy C, Kelly S. Winning at all costs: a review of risk-taking behaviour and sporting injury from an occupational safety and health perspective. Sport Med - Open [Internet]. 2019;5:15. Available from: https://sportsmedicine-open.springeropen.com/articles/10.1186/s40798-019-0189-9

10. Hassanzadeh-Rad A, Halabchi F. Stadiums as Possible Hot Spots for COVID-19 Spread. Asian J Sports Med. 2020; 
11. Stacey A, Atkins B. Infectious diseases in rugby players: Incidence, treatment and prevention [Internet]. Sport. Med. Adis International Ltd; 2000 [cited 2020 Jun 22]. p. 211-20. Available from: https://link.springer.com/article/10.2165/00007256-200029030-00005

12. Fenton LT, Pitter R. Keeping the body in play: Pain, injury, and socialization in male rugby. Res Q Exerc Sport. 2010;

13. Hokowhitu B, John Sullivan S, Williams T, R L. Rugby culture, ethnicity and concussion. MAI Rev [Internet]. 2008 [cited 2020 Jun 19];1. Available from: http://tvnz.co.nz/view/page/417227/730490

14. Pringle R, Markula P. No pain is sane after all: A foucauldian analysis of masculinities and men's experiences in rugby. Sociol Sport J. 2005;

15. Guldenmund FW. The nature of safety culture: A review of theory and research. Saf Sci. 2000;34:215-57.

16. Cooper MD. Towards a model of safety culture. Saf Sci [Internet]. 2000;36:111-36. Available from: https://linkinghub.elsevier.com/retrieve/pii/S0925753500000357

17. Haukelid K. Theories of (safety) culture revisited-An anthropological approach. Saf Sci. 2008;46:413-26.

18. Patel DR, Shivdasani V, Baker RJ. Management of sport-related concussion in young athletes. Sport. Med. 2005.

19. Kerr ZY, Register-Mihalik JK, Kroshus E, Baugh CM, Marshall SW. Motivations Associated with Nondisclosure of Self-Reported Concussions in Former Collegiate Athletes. Am J Sports Med. 2016;

20. Sparkes AC. Qualitative Research Methods in Sport, Exercise and Health [Internet]. Qual. Res. Methods Sport. Exerc. Heal. From Process to Prod. Routledge; 2013. Available from: http://ovidsp.ovid.com/ovidweb.cgi?T=JS\&PAGE=reference\&D=psyc11\&NEWS=N\&AN=2013-37848000

21. Smith B, McGannon KR. Developing rigor in qualitative research: problems and opportunities within sport and exercise psychology. Int Rev Sport Exerc Psychol [Internet]. 2018 [cited $2018 \mathrm{Jul}$ 28];11:101-21. Available from: https://www.tandfonline.com/doi/full/10.1080/1750984X.2017.1317357

22. Government of Ireland. Gov.ie - Return to Work Safely Protocol [Internet]. 2020 [cited 2020 Jul 1]. Available from: https://www.gov.ie/en/publication/22829a-return-to-work-safely-protocol/

23. Carraturo F, Del Giudice C, Morelli M, Cerullo V, Libralato G, Galdiero E, et al. Persistence of SARS-CoV2 in the environment and COVID-19 transmission risk from environmental matrices and surfaces. Environ Pollut. 2020;

24. Dimakatso R, Christa J van R, Lee P, Pierre V, Phatho Z, Jon P. Implications of COVID-19 for resumption of sport in South Africa. South African J Sport Med [Internet]. 2020 [cited 2020 Jul 6];32. Available from: https://journals.assaf.org.za/index.php/sajsm/article/view/8454

25. WHO. Health workers exposure risk assessment and management in the context of COVID-19 virus [Internet]. 2020. Available from: https://apps.who.int/iris/bitstream/handle/10665/331340/WHO2019-nCov-HCW_risk_assessment-2020.1-eng.pdf 
26. Hughes D, Saw R, Perera NKP, Mooney M, Wallett A, Cooke J, et al. The Australian Institute of Sport framework for rebooting sport in a COVID-19 environment. J. Sci. Med. Sport. 2020.

27. RTÉ Sport. New rugby rules for Covid-19 prevention approved [Internet]. RTÉ Sport. 2020 [cited 2020 Jun 22]. Available from: https://www.rte.ie/sport/rugby/2020/0528/1143129-new-rugby-rules-forcovid-19-prevention-approved/

28. Fuller CW. Developing a health surveillance strategy for professional footballers in compliance with UK health and safety legislation. Br J Sports Med. 1997;

29. Keeling MJ, Hollingsworth TD, Read JM. The Efficacy of Contact Tracing for the Containment of the 2019 Novel Coronavirus (COVID-19). medRxiv. 2020;

30. The Health Information and Quality Authority. Evidence sum mary for spread of COVID-19 by children Health Information and Quality Authority [Internet]. 2020. Available from: www.hiqa.ie

31. Health Protection Surveillance Centre. Epidemiology of COVID-19 in Ireland - Health Protection Surveillance Centre [Internet]. 2020 [cited 2020 Jun 29]. Available from: https://www.hpsc.ie/az/respiratory/coronavirus/novelcoronavirus/casesinireland/epidemiologyofcovid-19inireland/

32. HSA. BEHAVIOUR BASED SAFETY GUIDE DOING WHAT WE DO BETTER, SMARTER, SAFER. 2013.

33. Leroy H, Dierynck B, Anseel F, Simons T, Halbesleben JRB, McCaughey D, et al. Behavioral integrity for safety, priority of safety, psychological safety, and patient safety: A team-level study. J Appl Psychol. 2012;

34. Creighton DW, Shrier I, Shultz R, Meeuwisse WH, Matheson GO. Return-to-Play in Sport: A Decisionbased Model. Clin J Sport Med [Internet]. 2010 [cited 2018 Nov 20];20:379-85. Available from: http://content.wkhealth.com/linkback/openurl?sid=WKPTLP:landingpage\&an=00042752201009000-00012

35. Cao W, Fang Z, Hou G, Han M, Xu X, Dong J, et al. The psychological impact of the COVID-19 epidemic on college students in China. Psychiatry Res [Internet]. Elsevier Ireland Ltd; 2020 [cited 2020 Jul 26];287:112934. Available from: /pmc/articles/PMC7102633/?report=abstract

36. Holmes EA, O’Connor RC, Perry VH, Tracey I, Wessely S, Arseneault L, et al. Multidisciplinary research priorities for the COVID-19 pandemic: a call for action for mental health science. The Lancet Psychiatry. Elsevier Ltd; 2020. p. 547-60.

37. Li H, Moreland JJ, Peek-Asa C, Yang J. Preseason Anxiety and Depressive Symptoms and Prospective Injury Risk in Collegiate Athletes. Am J Sports Med. 2017;

38. Dijkstra HP, Pollock N, Chakraverty R, Ardern CL. Return to play in elite sport: A shared decisionmaking process. Br. J. Sports Med. 2017.

39. Garraway WM, Lee AJ, Hutton SJ, Russell EBAW, Macleod DAD. Impact of professionalism on injuries in rugby union. Br J Sports Med [Internet]. British Association of Sport and Excercise Medicine; 2000 [cited 2018 Nov 21];34:348-51. Available from: http://www.ncbi.nlm.nih.gov/pubmed/11049144

40. Chadwick S. From outside lane to inside track: Sport management research in the twenty-first century. Manag Decis. 2009; 
41. Hull JH, Loosemore M, Schwellnus M. Respiratory health in athletes: facing the COVID-19 challenge. Lancet Respir Med. 2020;

42. Bonow RO, Fonarow GC, O'Gara PT, Yancy CW. Association of Coronavirus Disease 2019 (COVID-19) with Myocardial Injury and Mortality. JAMA Cardiol. 2020.

43. Jin H, Hong $\mathrm{C}$, Chen S, Zhou Y, Wang $Y$, Mao L, et al. Consensus for prevention and management of coronavirus disease 2019 (COVID-19) for neurologists. Stroke Vasc Neurol. 2020;

44. Dunning E. Some Conceptual Dilemmas in the Sociology of Sport. In: Pfister-Binz RA and K, editor. Sociol Sport Theor Found Res Methods. Basle: Magglinger Symposium; 1972.

\section{Tables}


Table 1

Participants' Background Information

\begin{tabular}{|c|c|c|c|c|c|c|}
\hline Participant & $\begin{array}{l}\text { Position } \\
\text { Involved }\end{array}$ & $\begin{array}{l}\text { Team Level } \\
\text { (Highest) }\end{array}$ & $\begin{array}{l}\text { Job } \\
\text { Type }\end{array}$ & $\begin{array}{l}\text { Age } \\
\text { Group }\end{array}$ & Gender & $\begin{array}{l}\text { Elite Playing } \\
\text { Experience }\end{array}$ \\
\hline P1 & Management & Provincial & $\begin{array}{l}\text { Full- } \\
\text { time }\end{array}$ & $50-60$ & M & Yes \\
\hline P2 & Management & Provincial & $\begin{array}{l}\text { Full- } \\
\text { time }\end{array}$ & $30-40$ & $M$ & Yes \\
\hline P3 & Medical staff & National & $\begin{array}{l}\text { Full- } \\
\text { time }\end{array}$ & $30-40$ & $M$ & No \\
\hline P4 & Medical staff & University & $\begin{array}{l}\text { Part- } \\
\text { time }\end{array}$ & $20-30$ & $M$ & Yes \\
\hline P5 & Medical staff & University & $\begin{array}{l}\text { Part- } \\
\text { time }\end{array}$ & $30-40$ & $M$ & No \\
\hline P6 & $\begin{array}{l}\text { Coaching } \\
\text { staff }\end{array}$ & Provincial & $\begin{array}{l}\text { Part- } \\
\text { time }\end{array}$ & $20-30$ & $M$ & Yes \\
\hline P7 & Management & University & $\begin{array}{l}\text { Full- } \\
\text { time }\end{array}$ & $50-60$ & $M$ & Yes \\
\hline P8 & $\begin{array}{l}\text { Coaching } \\
\text { staff }\end{array}$ & University & $\begin{array}{l}\text { Part- } \\
\text { time }\end{array}$ & $20-30$ & $M$ & Yes \\
\hline P9 & $\begin{array}{l}\text { Coaching } \\
\text { staff }\end{array}$ & University & $\begin{array}{l}\text { Part- } \\
\text { time }\end{array}$ & $40-50$ & $M$ & Yes \\
\hline P10 & Management & National & $\begin{array}{l}\text { Full- } \\
\text { time }\end{array}$ & $40-50$ & $M$ & No \\
\hline P11 & $\begin{array}{l}\text { Coaching } \\
\text { staff }\end{array}$ & National & $\begin{array}{l}\text { Full- } \\
\text { time }\end{array}$ & $20-30$ & $M$ & Yes \\
\hline P12 & Medical staff & National & $\begin{array}{l}\text { Full- } \\
\text { time }\end{array}$ & $30-40$ & $F$ & No \\
\hline P13 & Medical staff & National & $\begin{array}{l}\text { Full- } \\
\text { time }\end{array}$ & $50-60$ & $M$ & No \\
\hline P14 & $\begin{array}{l}\text { Coaching } \\
\text { staff }\end{array}$ & National & $\begin{array}{l}\text { Full- } \\
\text { time }\end{array}$ & $30-40$ & $M$ & Yes \\
\hline P15 & $\begin{array}{l}\text { Coaching } \\
\text { staff }\end{array}$ & National & $\begin{array}{l}\text { Full- } \\
\text { time }\end{array}$ & $40-50$ & $M$ & Yes \\
\hline \multicolumn{7}{|c|}{ Management include referee, team manager, director, coordinator etc. } \\
\hline \multicolumn{7}{|c|}{ Medical staff include team doctor, physiotherapist, medical consultant, medical coordinator etc. } \\
\hline
\end{tabular}


Table 2

An extract of codebook

\begin{tabular}{|c|c|c|}
\hline Theme & Description & Example codes and relevant extracts \\
\hline $\begin{array}{l}\text { Players' } \\
\text { hygiene }\end{array}$ & $\begin{array}{l}\text { A statement describes } \\
\text { players' hygiene behaviours } \\
\text { such as PPE use and hand } \\
\text { washing etc. }\end{array}$ & $\begin{array}{l}\text { - Hand hygiene } \\
\text { We educate players on hand washing and provide } \\
\text { alcohol gel in camps and things like that. Because if } \\
\text { somebody gets a trouble, or gets the flu or chest } \\
\text { infection, they can't perform. } \\
\text { - Oral hygiene } \\
\text { they eat something dodgy and get a bug and it's all } \\
\text { gone. }\end{array}$ \\
\hline $\begin{array}{l}\text { Player } \\
\text { health } \\
\text { condition } \\
\text { surveillance }\end{array}$ & $\begin{array}{l}\text { A statement describes the } \\
\text { actions taken by rugby } \\
\text { support staff (e.g. medical } \\
\text { staff, referee etc.) to protect } \\
\text { player health }\end{array}$ & $\begin{array}{l}\text { - Interaction between players and medical staff } \\
\text { We had the physio on site and from an injury point } \\
\text { of view, you know, you're looked after on pitch, they } \\
\text { were, they were there all the time. } \\
\text { - Referee decision on safety-related situations } \\
\text { Referees are critical to health and safety. In fact, } \\
\text { they're probably the most important. Referees' first } \\
\text { job is to make sure that the game's run in a safe } \\
\text { manner } \\
\text { - Routinely health condition surveillance } \\
\text { Kidman is an online software, we spend a lot of } \\
\text { money on having every player is on there, every } \\
\text { player has a profile. And on it or their, in the illnesses } \\
\text { and everything is managed the training that they do. }\end{array}$ \\
\hline
\end{tabular}


Table 3

Final framework identifying OSH factors for elite rugby safe return to play

\begin{tabular}{|c|c|c|}
\hline Category & Theme & Codes \\
\hline \multirow[t]{2}{*}{$\begin{array}{l}\text { Micromanagement on health-and- } \\
\text { safety }\end{array}$} & Players' hygiene & $\begin{array}{l}\text { - Hand hygiene } \\
\text { - Oral hygiene }\end{array}$ \\
\hline & $\begin{array}{l}\text { Player health condition } \\
\text { surveillance }\end{array}$ & $\begin{array}{l}\text { - Interaction between players and } \\
\text { medical staff } \\
\text { - Referee decision on safety- } \\
\text { related situations } \\
\text { - Health condition surveillance } \\
\text { routine }\end{array}$ \\
\hline \multirow[t]{3}{*}{$\begin{array}{l}\text { Player health-and-safety awareness } \\
\text { improvement }\end{array}$} & $\begin{array}{l}\text { Player awareness } \\
\text { education }\end{array}$ & $\begin{array}{l}\text { - Young players may feel } \\
\text { invulnerable } \\
\text { - Do not show pain }\end{array}$ \\
\hline & $\begin{array}{l}\text { Players' awareness of } \\
\text { reporting }\end{array}$ & $\begin{array}{l}\text { - Player reports unwellness } \\
\text { symptoms } \\
\text { - Player hides unwellness } \\
\text { symptoms }\end{array}$ \\
\hline & RTP after unwellness & $\begin{array}{l}\text { - Player decision on RTP } \\
\text { - Medical staff decision on RTP } \\
\text { - Collaborative decision on RTP }\end{array}$ \\
\hline Rugby's Physical Contact Nature & $\begin{array}{l}\text { Rugby physical contact } \\
\text { nature }\end{array}$ & $\begin{array}{l}\text { - Collisions } \\
\text { - Tackles }\end{array}$ \\
\hline
\end{tabular}

\section{Figures}


Introductory script for the interviews:

I would like to thank you for participating in this interview. As I have mentioned previously, my study is based on exploring methods of evaluating health-and-safety awareness in elite rugby.

Our interview today will last approximately 45 minutes, during which I will ask you about your experiences in elite rugby and your opinions regarding rugby players' health-and-safety awareness. [Review aspects of the consent form]

You completed a consent form indicating that I have (or do not have) your permission to audio-record our conversation. Are you still willing (or not) to have our conversation recorded? _ ${ }^{\mathrm{Yes}}$ _No.

Before we begin the interview, do you have any questions?

If any questions arise at any point during this interview, feel free to ask them at any time. I will be more than happy to answer your questions if I can; if not, I can direct my supervisors to respond to your question.

\section{Questions}

1. Could you tell me your understanding of health-and-safety in rugby?

2. How do you think health and safety in elite rugby differs from that in other occupations?

3. Could you tell me about some important health and/or safety practices or procedures implemented in your organisation?

4. Can you tell me how, in your organisation, management personnel communicate regarding health-andsafety practices?

5. Can you tell me how management personnel in your organisation communicate with players regarding health and safety?

6. To what extent do you think that players are committed to implementing health-and-safety practices?

7. What factors do you think may influence health and/or safety practices within your organisation?

8. Have you noticed any health- or safety-related issues in regard to stakeholders outside of your organisation?

9. What do you think are the primary challenges in regard to ensuring players' health-and-safety?

10. In elite rugby, what do you think should be included in health-and-safety evaluations?

\section{Figure 1}

Interview Protocol 